\title{
Assessment of the quality of life of pediatric patients at a center of excellence in dermatology in southern Brazil
}

\author{
Avaliação da qualidade de vida dos pacientes pediátricos de um centro de \\ referência em dermatologia no sul do Brasil
}

Magda Blessmann Weber ${ }^{1}$
Clarissa Prieto Herman Reinehr ${ }^{3}$

Daniel Lorenzini ${ }^{2}$

Bárbara Lovato ${ }^{4}$

ABstRACT: BACKGROUND: Skin diseases cause negative impact on the emotional state, social relationships and daily activities, due to the stigma caused by the appearance of the lesions.

OвJестіvE: This study aimed to assess the quality of life of pediatric patients with skin diseases attending a dermatology service, compare the scores obtained among the dermatoses found in the sample and associate them to the variables, in addition to observing how the skin disease specifically affects quality of life.

MEтHоDS: Cross-sectional study, with patients between 5 and 16 years attending the Dermatology Service of the University of Health Sciences of Porto Alegre, Brazil, between July 2010 and February 2011. The data collection instruments were the Children's Dermatology Life Quality Index questionnaire and the AUEQI questionnaire.

RESULTS: A total of 161 patients were interviewed, with mean age of 9,66 years. The main dermatoses were atopic dermatitis (29.8\%), warts (13\%) and molluscum contagiosum (7.5\%). Chronic diseases (73.9\%) were the most prevalent. The overall mean Children's Dermatology Life Quality Index score was 5.01 for chronic dermatoses and 2.07 for acute illnesses, indicating a compromised quality of life among chronically ill patients. The comparison between the scores obtained with the AUEQI scale and the Children's Dermatology Life Quality Index scores indicates that the overall quality of life is less affected than the specific quality of life related to the dermatosis.

Conclusions: The data presented reinforce how important it is that the patients, their families and caregivers understand the symptoms, triggers and treatment of the skin disease in question. This information facilitates adherence to the treatment and justifies the conduct adopted by the dermatologist.

Keywords: Child; Dermatology; Quality of life; Skin diseases

Resumo: Fundamentos: Doenças dermatológicas, em razão dos estigmas pela aparência das lesões, são fonte de impacto negativo no estado emocional, relações sociais e atividades cotidianas.

OвjETIVOs: Este estudo objetiva avaliar a qualidade de vida nos pacientes dermatológicos pediátricos em um centro de referência em dermatologia, comparar os índices de qualidade de vida entre as dermatoses e associá-los às variáveis, além de avaliar de que forma as dermatoses afetam a qualidade de vida especificamente.

MÉTodos: Estudo analítico transversal, pacientes entre 5 e 16 anos, do Serviço de Dermatologia da Universidade Federal de Ciências da Saúde de Porto Alegre, entre julho de 2010 e fevereiro de 2011. Instrumentos utilizados: questionário Índice Pediátrico de Qualidade de Vida em Dermatologia e escala AUQEI.

Resultados: Um total de 161 pacientes, média de idade de 9,66 anos. As principais dermatoses foram dermatite atópica $(29,8 \%)$, verrugas vulgares (13\%) e molusco contagioso (7,5\%). Doenças crônicas $(73,9 \%)$ foram mais prevalentes. A média do Índice Pediátrico de Qualidade de Vida em Dermatologia de 5,01 para dermatoses crônicas, e de 2,07 em agudas, indicando maior comprometimento da qualidade de vida entre os pacientes cronicamente enfermos. A comparação entre os escores obtivos com a escala AUEQI e o Índice Pediátrico de Qualidade de Vida em Dermatologia indicam que a qualidade de vida global é afetada com menor intensidade do que a relacionada especificamente à dermatose.

Conclusĩo: Os dados obtidos reforçam a importância do entendimento dos sintomas, desencadeantes e da terapêutica da dermatose em questão pelos pacientes, por seus familiares e por seus cuidadores. Tais infomações facilitam a aderência ao tratamento e justificam a conduta adotada pelo dermatologista.

Palavras-chave: Criança; Dermatologia; Dermatopatias; Qualidade de vida

Received on 02.12 .2011

Approved by the Advisory Board and accepted for publication on 24.01.2012.

* Work performed at the Dermatology Service of the Universidade Federal de Ciências da Saúde de Porto Alegre (UFCSPA) - Porto Alegre (RS), Brazil. Conflict of interest: None

Financial funding: None

PhD - Teacher at the Dermatology Service of the Universidade Federal de Ciências da Saúde de Porto Alegre (UFCSPA) - Porto Alegre (RS), Brazil. Physician - Contracted Physician and Guest Preceptor of the Dermatology Service of the Universidade Federal de Ciências da Saúde de Porto Alegre (UFCSPA) Porto Alegre (RS), Brazil.

Physician - Resident Physician of the Dermatology Service of the Hospital de Clínicas de Porto Alegre (HCPA) - Porto Alegre (RS), Brazil. Student of the Medicine Graduation Course by the Universidade Federal de Ciências da Saúde de Porto Alegre (UFCSPA) - Porto Alegre (RS), Brazil. 


\section{INTRODUCTION}

Due to the stigma caused by the appearance of the lesions, skin diseases often produce negative impact on the emotional state, social relationships and daily activities of the patients. ${ }^{1}$ It is estimated that about one third of dermatology patients have emotional aspects associated with their disease. ${ }^{2}$ Moreover, it is important to note that there is a strong relationship between low self-esteem and childhood dermatosis, a factor that can aggravate the psychosocial complications associated with the disease. ${ }^{3}$

There is a close connection between the skin and the central nervous system, since they originate from the same embryonic germ cell layer, the ectoderm. This fact provides the basis for the assumption that the skin and the brain can influence one another, and this assumption is reinforced by studies of numerous skin conditions such as systemic lupus erythematosus, psoriasis, acne and alopecia areata, in which an unbalanced mental state may both trigger and/or be exacerbated by an underlying skin disease. ${ }^{3.5}$ Health status is influenced by the physical, psychological and social conditions, with variable inter-relationships between these domains, which should be followed when treating the patient. In addition, the individual's health status is strongly related to his /her quality of life and appreciation of the subject as a whole and an interdisciplinary intervention are essential for any therapy to be effective in improving the quality of life of the patient.

Given this situation, the question arises as to which factors, conditions or situations produce greater impact on the quality of life of dermatology patients. A study conducted in 2005 by a group of researchers from the Department of Dermatology at UFCSPA (Federal University of Health Sciences of Porto Alegre), suggests a greater degree of psychological distress in patients with chronic skin diseases and unfavorable aesthetic appearance. ${ }^{6}$

A review of the literature on the subject shows there is a scarcity of publications on the consequences of dermatological diseases in the pediatric population, a group that deserves attention given that dermatoses with a negative psychological impact can trigger problems in the cognitive process, affecting learning at school, as well as difficulties in the social and family environment, and can trigger from mild and transient disorders to changes in mood and personality. Even interest in sports may be adversely affected by skin diseases, due to their strong relationship with low self-esteem in children. ${ }^{7}$ In a longitudinal study conducted in the United Kingdom, sixty-four pediatric patients with pruritus, atopic dermatitis or psoriasis, an evident relationship was found between clinical deterioration and adverse life events, with clinical improvement occurring after five years of follow-up when the stressors were removed. ${ }^{8}$
At the same time, the importance of this issue is reflected by the recent inclusion of estimates of the quality of life in pediatric patients as a third dimension to be studied within randomized clinical trials, in addition to the efficacy and safety of medications. ${ }^{9}$ Quality of life is a term that is open to interpretation and which seeks to name some of the features of the human experience and is considered the central factor that determines the patient's subjective feeling of wellbeing. ${ }^{10,11}$ For some authors, the concept of quality of life (QoL) encompasses all aspects that surround the temporal diagnosis and treatment of a disease and that extends beyond the medical issues, including lifestyle, community and family life. Another possible definition refers to QoL as the possession of the necessary resources to meet the individual needs and desires, participation in activities enabling personal development, self-actualization and satisfactory comparison between oneself and others. The United Nations Convention on the Rights of Children recognizes their right to the highest level of health, leisure and education as well as the right to a standard of living suited to their physical, mental, spiritual, moral and social development. 12 We therefore believe that all these variables make up the definition of quality of life of the child, which relate in a complex and dynamic manner, by which suffering experienced in one of these areas may have consequences for the others.

Several indicators have been created in order to assess the welfare of children, especially the development of their cognitive and social behavior. In assessing the welfare of children and adolescents, it is essential to appreciate the subjective experience, not just their living conditions, since the relationship between objective conditions and psychosocial state is often asymmetrical. Hence, the best way to carry out this analysis is through the individual's own description of what he/she is feeling at a particular point in his/her life. For sick children and adolescents, in particular, "wellbeing" can imply a wide range of feelings which are variable in relationship to their health and strongly subject to change, being influenced by everyday events and chronic problems. Consequently, it is important to create a standard questionnaire applied to the patient in order to measure the quality of life. ${ }^{12,13}$

The Children's Dermatology Life Quality Index (CDLQI) allows a simple, compact and uniform assessment of patients with skin diseases in general, in which higher scores indicate poorer disease-related quality of life. ${ }^{14}$ By contrast, Quality of Life Scale for Children (AUQEI - Autoquestionnaire qualité de vie enfant em imagé) seeks to assess the subjective feeling of well-being of the individual, by examining the child's feelings about their satisfaction with various aspects of 
life such as health and family relationships. ${ }^{15}$

Since skin diseases are usually evident, have strong social repercussions and thus worsen the quality of life. In order to establish a full and effective therapy it is necessary to appreciate them in terms of their overall effect on the individual. In this regard, the assessment tools available allow a better understanding of a child's experience when faced by the disease, in particular how the disease affects the quality of life of the individual. More data on this topic could lead to improved assessments and therapeutic approaches for the pediatric population. ${ }^{15}$

From a clinical perspective, the importance of assessing the quality of life becomes evident when, during the dermatological consultation, the pediatric patients or their parents refer to the effects the symptoms have on the lives of the patients, on interpersonal relationships within school and family life as well as on the patient's perception of well-being as an important complaint. ${ }^{16-18}$

This study aimed to assess the quality of life of pediatric patients with skin diseases attending a dermatology service, compare the quality of life scores obtained among the dermatoses found in the sample and associate them to variables such as age, sex and length of time in treatment, in addition to observing how the skin disease specifically affects quality of life.

\section{MATERIALS AND METHODS}

It is a cross-sectional study, with patients between 5 and 16 years attending the Dermatology Service of the University of Health Sciences of Porto Alegre, Rio Grande do Sul, Brazil, between July 2010 and February 2011. Along with their adult companions, they were invited to participate in the study and informed by the interviewer as to its purpose and the confidentiality of any personal information and subsequently asked to consent to participate in the study.

The inclusion criteria for patient selection were: age from five to sixteen years, no disease that could interfere with cognition and no diagnosis of psychiatric illness. The study was previously approved by the Ethics in Research Committee of UFCSPA for use in the service.

The data collection instruments used were the CDLQI questionnaire and the AUEQI questionnaire.

The Children's Dermatology Life Quality Index (CDLQI) is an instrument consisting of ten items divided into six categories: symptoms and feelings, daily activities, leisure, work/school, personal relationships and treatment. The responses generate scores between 0 (zero) and 3 (three) and the final calculation is a simple sum of these scores, with higher levels indicating disease-related poorer quality of life. ${ }^{1}$ The
CDLQI instrument was previously translated and validated in Brazil by Pratti et al., and in addition to providing a general index of the patient's quality of life related to skin disease, this questionnaire facilitates an assessment of how each area of the patient's life is being affected. ${ }^{14}$

The Quality of Life Scale for Children (AUQEI) was developed by Manificat \& Dazord and validated and translated by Francis B. Assumpção Jr et al.. It provides a profile of the level of satisfaction and wellbeing of the child in different situations, based on four figures representing the answers: very happy, happy, unhappy and very unhappy, associated with several domains of quality of life. ${ }^{15}$

The data were stored in an anonymous database and analyzed using SPSS 17 . The analysis of the variables was performed using Student's test, considering an association of $\mathrm{p}<0.05$ significant.

\section{Ethical considerations}

The researchers signed a term of commitment related to the confidentiality of the data use, in accordance with the resolution CNS 196/96. At each contact, the free informed consent term was read to the patient and his/her companion and only with the agreement of the patient's companion and the patient were the questionnaires applied. The patients were informed of the nature and objectives of the project within their cognitive capacity to understand. The desire not to participate in the study, when manifested by the child, was upheld. The consent form was signed by the companion and also by the child when deemed able to sign his/her name.

\section{RESULTS}

A total of 161 patients were interviewed, $42.2 \%$ male and $57.8 \%$ females, aged between 5 and 16 years, with a mean age of 9.66 years, standard deviation 2,979. Regarding family status, $97.8 \%$ of the patients were living with their parents and families and $2.2 \%$ of the patients lived in shelters.

The main dermatoses found were atopic dermatitis (29.8\%), common warts (13\%), molluscum contagiosum $(7.5 \%)$, psoriasis $(4.3 \%)$, alopecia areata (3.5\%) and vitiligo (2 5\%). In the remainder of the sample, among the less prevalent (ranging from 0.6 to $12 \%$ ) dermatoses were dyshidrosis, congenital nevus, onychomycosis, ectodermal dysplasia, skin manifestations of food allergy, hemangioma, lichen sclerosus, keloids and hypertrophic scars. Chronic diseases had a higher prevalence (73.9\%) compared to acute manifestations $(26.1 \%)$, with a mean duration of acne of 4.17 years and mean treatment period of 1.78 years.

Regarding the type of treatment being applied, $60 \%$ were using only topical treatments, $3.1 \%$ used 
only systemic treatment and $21.2 \%$ were using topical and systemic medications. When asked about unconventional behavior, $14.8 \%$ of patients reported the use of alternative treatments such as incantations (6.1\%), homeopathy $(3.7 \%)$, and use of charms and herbal teas and plants.

The AUQEI questionnaire showed that the patients have a good understanding of quality of life. Thirty-three and a half percent $(33.5 \%)$ of them had an impaired quality of life. Although male patients showed a better quality of life than females, the difference was not statistically significant (odds ratio 0.61 , CI 0.36 to 1.54$)$.

With the CDLQI questionnaire, $51 \%$ showed a slight impact on quality of life, $18 \%$ a moderate impact, $5 \%$ a great impact, $1.2 \%$ an extreme impact and $24.8 \%$ of patients showed no change in quality of life. The overall mean CDLQI score was 5.01 for chronic dermatoses and 2.07 for acute illnesses, indicating a compromised quality of life among chronically ill patients. There was no statistically significant difference between sexes in the CDLQI questionnaire, although males again showed the best quality of life indicators (odds ratio 0.9 , CI 0.37 to 1.41 ).

A specific analysis of the most common dermatoses found within the sample in relation to QoL with the respective results is presented in table 1 .

When comparing the CDLQI between the various age groups, the worst rates seen to occur at the ages of 6 years (7.28), 7 years (6.14) and 15 (5.27), all of which are above the average for the sample (4.52).

In relation to specific domains of the CDLQI, there is an important difference between the different domains assessed (Table 2).

Significant differences were found when specific areas of CDLQI were analyzed in relation to chronic and acute diseases (Table 3 ).

In the feelings domain, the highest scores, representing a worse impact on QoL, were found among the patients with chronic diseases.

In the leisure domain of the CDLQI, $59.5 \%$ of acutely ill patients and $52.1 \%$ of those with chronic diseases reported no impact in this domain, again showing better rates in this regard among those with acute illness.

In the domain of personal relationships, only the chronic patients had scores indicating a great effect on QoL.

In the domains of school/vacations and the quality of sleep the same trend noted in the previous domains can be seen, with the worst rates for the chronic diseases.

As regards the treatment domain, the diseases with the worst rates were psoriasis $(57.2 \%)$, common warts (36.9\%), atopic dermatitis (36\%) and mollus-
TABLE 1: Diminished QoL in the various dermatosis analyzed using the CDLQI and AUQEI questionnaires

\begin{tabular}{lll}
\hline DERMATOSES & AUQEI \% & CDLQI \% \\
\hline Atopic dermatitis & 36 & 88 \\
Common warts & 47.3 & 68.4 \\
Molluscum contagiosum & 33 & 75 \\
Psoriasis & 28 & 85 \\
Vitiligo & 0 & 100 \\
\hline
\end{tabular}

TABLE 2: Effect on the quality of life (QoL) in the various domains of the CDLQI

\begin{tabular}{lll} 
CDLQI DOMAINS & QoL affected & $\begin{array}{l}\text { QoL not } \\
\text { affected }\end{array}$ \\
\hline Feelings & $82.7 \%$ & $27.3 \%$ \\
Personal relations & $33.5 \%$ & $66.5 \%$ \\
School and vacations & $19.9 \%$ & $80.1 \%$ \\
Sleep & $34.8 \%$ & $65.2 \%$ \\
Leisure & $66 \%$ & $54 \%$ \\
\hline
\end{tabular}

cum contagiosum (17\%).

In relation to specific domains of the AUEQI, those that showed the worst responses in relation to the suffering triggered were: being away from the family $(79.5 \%)$, playing alone $(69.5 \%)$, staying in hospital (68.3\%), and taking medication (50.9\%). Watching television, being in the presence of the mother, father and grandparents, the school holidays and the birthday were the domains which reported the greatest satisfaction (Graph 1).

Only $13 \%$ were only children, and no statistically significant difference was found between their CDLQI scores when compared to those of patients who had siblings. Patients who had siblings and were firstborn had lower CDLQI scores, indicating greater degree of suffering related to acne when the patient is not the first child, though there was no statistical significance, with an odds ratio of 1.36 (CI 0.31 - 1, 34). The same was observed in the AUEQI questionnaire, with the lowest rates occurring among patients who were not first born, but there was no statistical significance, with an odds ratio of 3.1 (CI 0.26 to 1.7 ).

\section{DISCUSSION}

The most affected domain in the CDLQI questionnaire was that related to feelings, while the least affected was that which refers to school and vacations. Thus, it is possible to infer that psycho-affective disorders that result from the signs and symptoms of skin diseases are more frequent than those related to school performance. Although school performance may worsen momentarily during very intense exacer- 
TABLE 3: Relationship between specific domains of the CDLQI and their variation in chronic and acute diseases

\begin{tabular}{|c|c|c|c|c|c|c|c|c|c|c|}
\hline \multirow{2}{*}{$\begin{array}{l}\text { CDLQI } \\
\text { DOMAINS } \\
\text { Disease }\end{array}$} & \multicolumn{2}{|c|}{$\begin{array}{l}\text { QoL not } \\
\text { affected }\end{array}$} & \multicolumn{2}{|c|}{$\begin{array}{l}\text { QoL } \\
\text { slightly } \\
\text { affected }\end{array}$} & \multicolumn{2}{|c|}{$\begin{array}{l}\text { QoL } \\
\text { moderately } \\
\text { affected }\end{array}$} & \multicolumn{2}{|c|}{$\begin{array}{l}\text { QoL } \\
\text { greatly } \\
\text { affected }\end{array}$} & \multicolumn{2}{|c|}{$\begin{array}{l}\text { QoL } \\
\text { extremely } \\
\text { affected }\end{array}$} \\
\hline & A* & $C^{*}$ & A & C & $\mathbf{A}$ & C & A & C & A & C \\
\hline FEELINGS & $33.5 \%$ & $25.2 \%$ & $57.1 \%$ & $46.9 \%$ & $9.4 \%$ & $21.7 \%$ & $0 \%$ & $4.2 \%$ & $0 \%$ & $2 \%$ \\
\hline PERSONAL RELATIONS & $79 \%$ & $62.1 \%$ & $19.5 \%$ & $26 \%$ & $2.3 \%$ & $9.4 \%$ & $0 \%$ & $2.5 \%$ & $0 \%$ & $0 \%$ \\
\hline SCHOOL AND & $90.8 \%$ & $76.4 \%$ & $4.6 \%$ & $17 \%$ & $4.6 \%$ & $3.3 \%$ & $0 \%$ & $3.3 \%$ & $0 \%$ & $0 \%$ \\
\hline \multicolumn{11}{|l|}{ VACATIONS } \\
\hline SLEEP & $73 \%$ & $62.1 \%$ & $19.9 \%$ & $27 \%$ & $0 \%$ & $0 \%$ & $7.1 \%$ & $9.2 \%$ & $0 \%$ & $1.7 \%$ \\
\hline LEISURE & $59.5 \%$ & $52.1 \%$ & $26.1 \%$ & $25.5 \%$ & $14.4 \%$ & $14.2 \%$ & $0 \%$ & $5.8 \%$ & $0 \%$ & $2.4 \%$ \\
\hline TREATMENT & $71.5 \%$ & $65.5 \%$ & $16.6 \%$ & $25.3 \%$ & $0 \%$ & $0 \%$ & $7.1 \%$ & $4.2 \%$ & $4.8 \%$ & $5 \%$ \\
\hline
\end{tabular}

*A: Acute disease. **C: Chronic disease

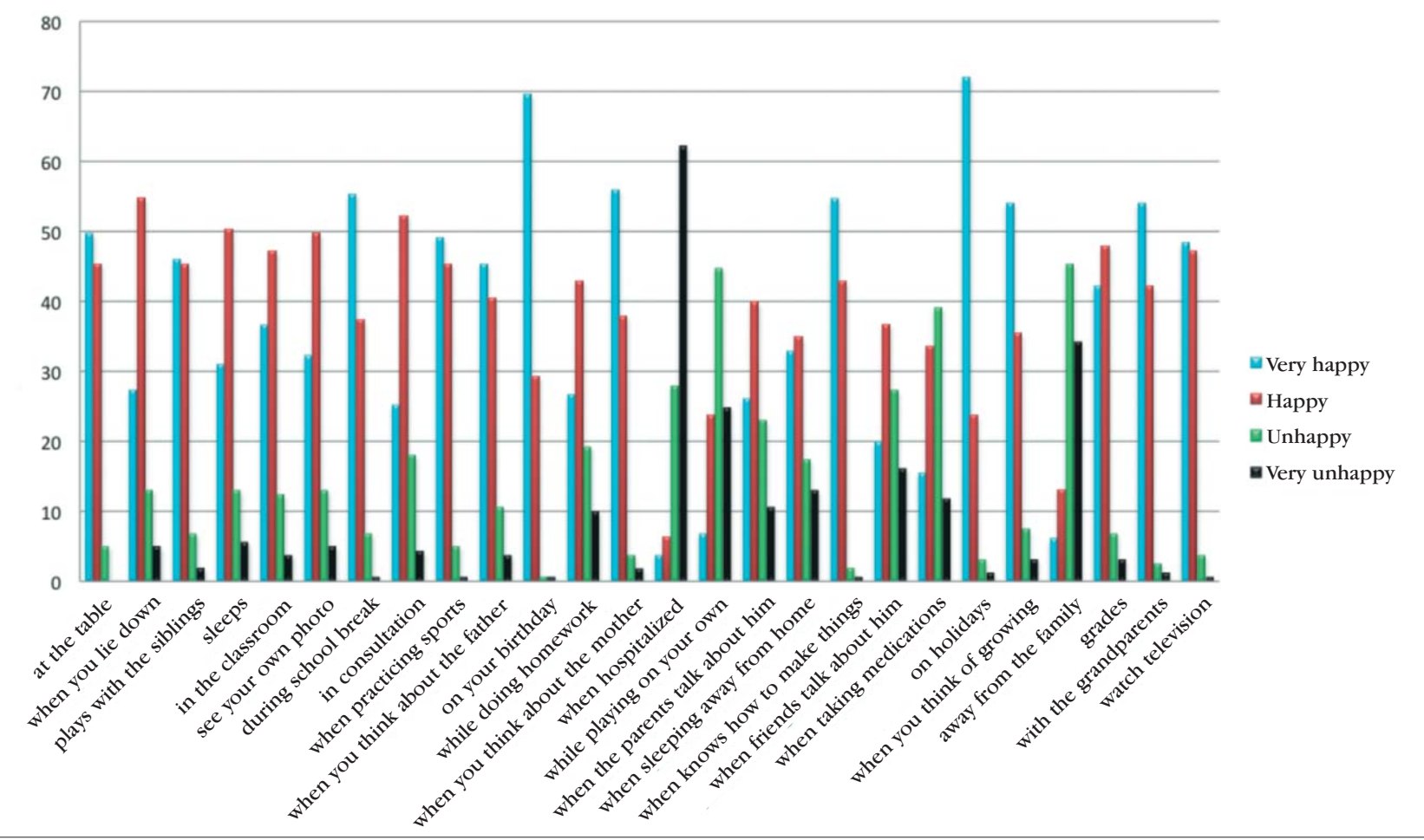

GraPh 1: AUQEI Domains

bations of a chronic or acute illness, it is important to be aware of the fact that the pediatric patient understands that in certain situations he/she can justify his/her behavior or change the opinion of their caregivers by overestimating the symptoms of their skin disease. As an example, we can mention the sudden worsening of pruritus in atopic patients when they are deprived of something and the sudden improvement when the patient's will is fulfilled. The good development of the child, however, demands that parents be aware of the possibility of this phenomenon occurring and encourage the children to also take responsibility for managing their disease.
Although there was a tendency towards the QoL scores to be worse among males, it did not attain statistical significance, possibly because of the sample size used. However, this trend suggests that more studies should be conducted to assess this aspect.

Regarding the differences observed between the different age groups, with the worst rates at 6,7 and 15 years, more extensive studies need to be carried out in order to confirm this trend, particularly while isolating age from other factors such as specific dermatoses and their chronicity. However, one might begin by asking about the possible impact of starting schooling and of adolescence and their relationship 
with the greater impairment of quality of life due to skin diseases.

In all the specific domains of the CDLQI, analysis showed that, when compared to acute diseases, chronic diseases produce a higher degree of impairment in quality of life specifically related to the dermatosis. This difference corroborates data from earlier reports and is of clinical importance since it draws our attention to the frequent need to ensure psychiatric support for children with chronic dermatoses in order to minimize their suffering and the social and emotional limitations that may result from the disease.

The comparison between the scores obtained with the AUEQI scale and the CDLQI scores indicates that the overall quality of life is less affected than the specific quality of life related to the dermatosis. This result was maintained when each skin diseases was analyzed separately.

\section{CONCLUSIONS}

Chronic diseases cause a greater degree of suffering during treatment and worse rates of quality of life. Other factors, such as age, also influence the impact of the dermatosis on the quality of life of pediatric patients, and deserve attention in the clinical practice.

The data presented here reinforce how impor- tant it is that the patients, their families and caregivers understand the symptoms, triggers and treatment of the skin disease in question. This information facilitates adherence to the treatment and justifies the conduct adopted by the dermatologist. The correct understanding of the pathophysiology of the skin disease not only increases adherence to treatment, but can also mitigate the symptoms, since it allows the patient to avoid the triggers of his/her dermatosis.

It also highlights the importance of addressing the possible existence of emotional effects of dermatoses in the daily life of the child during the dermatological consultation. As a result of which, it may be necessary to adopt a multidisciplinary approach and refer the patient to other specialists in order to meet his/her needs. Pediatric patients may feel embarrassed or uncomfortable about freely exposing their difficulties and anxieties about the disease, but it is the experience of this study that when asked about these issues and when they are given room to do so, they communicate and share their experiences and difficulties. Helping them make sense and cope with these situations, through expanding their own knowledge of their skin disease, and counseling patients on how they and their parents should proceed in the face of adversity, represent an important part of the dermatologist's role.

\title{
REFERENCES
}

1. Finlay AY, Khan GK. Dermatology life quality index (DLQI) - a simple practical measure for routine clinical use. Clin Exp Dermatol. 1994;19:210-6.

2. Gupta MA, Gupta AK. Psychodermatology: an update. J Am Acad Adermatol 1996:34: 1030-1046.

3. Folks DG, Warnock JK. Psychocutaneous disorders. Curr Psychiatry Rep. 2001;3: 219-25.

4. Walker C, Papadopoulos L, editors. Psychodermatology: the psychological impact of skin disorders. New York: Cambridge University Press, 2005

5. Tucker P. Bald is beautiful?: the psychosocial impact of alopecia areata. J Health Psychol. 2009;14:142-51.

6. Taborda MLVV, Weber MB, Freitas ES. Avaliação da prevalência de sofrimento psíquico em pacientes com dermatoses do espectro dos transtornos psicocutâneos. An Bras Dermatol. 2005:80:351-4.

7. Loney T, Standage M, Lewis S. Psychosocial Effects of Dermatological-related Social Anxiety in a Sample of Acne Patients. J Health Psychol. 2008:13:47-54.

8. Capoore HS, Rowland Payne CM, Goldin D. Does psychological intervention help chronic skin conditions? Postgrad Med J. 1998;74:662-664.

9. Bech P. Quality of life measurement in the medical setting. Eur Psychiatry. 1995;10 Suppl 3:83s-5s.

10. Guyatt GH, Feeny $\mathrm{DH}$, Patrick DL. Measuring health-related quality of life. Ann Intern Med. 1993;118:622-9.

11. Newell P. The United Nations Convention and children's rights in the UK. London: National Children's Bureau, 1993.

12. Gaspar T, Riberio JLP, Leal I. Qualidade de vida e bem-estar em crianças e adolescentes. Rev Bras Ter Cogn. 2006;2:47-60

13. Kadyk DL, McCarter K, Achen F, Belsito DV. Quality of life in patients with allergic contact dermatitis. J Am Acad Dermatol. 2003;49:1037-48.

14. Prati C, Comparin C, Catucci BJ, Ferreira CT. Validação para o português falado no Brasil do instrumento Escore da Qualidade de Vida na Dermatologia Infantil (CDLQI). Med Cutan Iber Lat Am. 2010;38:229-33.

15. Assumpção Junior FB, Kuczynski E, Sprovieri MH, Aranha EMG. Escala de avaliação de qualidade de vida: (AUQEI - Autoquestionnaire Qualité de Vie Enfant Imagé) validade e confiabilidade de uma escala para qualidade de vida em crianças de 4 a 12 anos. Arq Neuro-Psiquiatr. 2000;58:119-27.

16. Scarpelli AC, Paiva SM, Pordeus IA, Varni JW, Viegas CM, Allison PJ. Pediatric Quality of Life InventoryT (PedsQLT) family impact module: reliability and validity of the Brazilian version. Health Qual Life Outcomes. 2008;6:35.

17. Gerth VW. Quality of life, shoud we bother? Allergy. 2003:58:284-6.

18. Orzechowski NM, Davis DM, Mason TG 3rd, Crowson CS, Reed AM. Health-related quality of life in children and adolescents with juvenile localized scleroderma. Rheumatology (Oxford). 2009;48:670-2

\author{
MAILING ADDRESS: \\ Clarissa Prieto Herman Reinehr \\ Rua Sarmento Leite, 245 \\ 90050-170 Porto Alegre, RS \\ E-mail: clazinha-br@botmail.com
}

How to cite this article: Weber MB, Lorenzini D, Reinehr CPH, Lovato B. Assessment of the quality of life of pediatric patients at a center of excellence in dermatology in southern Brazil. An Bras Dermatol. 2012;87(5):697-702. 